\title{
Measurement of Kidneys in Sudanese Children up to Five Years Old Using Ultrasonography: Age as Predictor for Renal Length Measurement
}

\author{
Awadia Gareeballah ${ }^{1,2}$; Mohammed Elfatih Adam ${ }^{2}$; Moawia Gameraddin ${ }^{1 *}$; Nagla Elsir \\ Mohammed $^{2}$; Alaa Ebrahim ${ }^{3}$; Asma Elamin ${ }^{4}$; Mowada Burai Mohamed ${ }^{2}$ \\ ${ }^{1}$ Taibah University, Al-Madinah Al-Munawarah, Saudi Arabia \\ ${ }^{2}$ Alzaiem Alazhari University, Khartoum, Sudan \\ ${ }^{3}$ University of Medical Sciences and Technology, Khartoum, Sudan \\ ${ }^{4}$ Sudan University of Science and Technology, College of Medical Radiological Sciences, Khartoum, Sudan
}

\begin{abstract}
Background: A change in renal length may be evidence of many renal diseases. The aim of our study was to produce reference ranges for renal length in Sudanese children up to 5 years of age using ultrasonography.

Methods and Results: This cross-sectional study was done to measure the normal size of kidneys in pediatrics up to 5 years of age using ultrasound. The study was conducted at Khartoum state in the Emergency Department of Albuluk Pediatric Hospital and Jafar Ibn Ouf Referral Pediatric Hospital from March to June 2018. The study included 101 Sudanese children up to 5 years with normal renal function tests and urine analysis. All ultrasound examinations of the kidneys were performed on a GE Logiq F6 Ultrasound Machine. The longitudinal measurement was obtained from the coronal section, while thickness and width were measured in the transverse section. The study revealed that mean measurements of the right kidney (RK) were $6.74 \pm 1.16$ $\mathrm{cm}, 3.12 \pm 0.68 \mathrm{~cm}$, and $2.59 \pm 0.58 \mathrm{~cm}$ for length, width, and anteroposterior diameter, respectively, and for the left kidney (LK) $6.98 \pm 1.10 \mathrm{~cm}, 3.25 \pm 0.65 \mathrm{~cm}$, and $2.74 \pm 0.60 \mathrm{~cm}$, respectively. There was no significant difference in renal length according to gender. The study concluded that the renal length in pediatric up to 5 years old can be predicted by age using the following regression equations: $R K$ length $=0.0422 \times a g e+5.4182 \mathrm{~cm}\left(\mathrm{R}^{2}=0.4636\right)$, LK length $=0.0392 \times$ age $+5.7472 \mathrm{~cm}\left(\mathrm{R}^{2}=0.4539\right)$.

Conclusion: The study found a significant correlation between RK, LK length and age ( $\mathrm{r}=0.68$ for RK and $\mathrm{r}=0.67$ for $\mathrm{LK}, P$ $<0.01)$. Age is an important influencing factor for assessing kidney length since there is a strong, significant correlation between age and kidney length. (International Journal of Biomedicine. 2020;10(3):226-230.)
\end{abstract}

Key Words: kidney length $\bullet$ ultrasound $\bullet$ age $\bullet$ height $\bullet$ weight

\section{Abbreviations}

BMI, body mass index; KL, kidney length; RK, right kidney; LK, left kidney; RKL, RK length; LKL, LK length

\section{Introduction}

A change in renal length may be evidence of many renal diseases, so it is essential to know the average reference values in children concerning their age, gender, height, weight, and

*Corresponding author: Associate Professor Moawia Gameraddin, Department of Diagnostic Radiologic Technology, Faculty of Applied Medical Sciences, Taibah University, Al-Madinah Al-Munawarah, Saudi Arabia.Email: gameradinm@gmail.com
BMI. Several studies suggested that there is a good correlation between KL and body parameters such as BMI, weight, height, and age. Sex does not affect kidney dimensions in pediatrics; in practice, the most used charts are KL according to age.$^{(1)}$ One of the previous studies stated that the most influential factor among the other values is height. Furthermore, considerable correlations were found between KL and height, age, weight, and body surface area. The rapid growth of height in children during the first two years was primarily associated with a similar increase in KL, suggesting that height should be 
considered an essential factor correlating with renal length. ${ }^{(2)}$

The Sudanese population differs from others in body habitus. Therefore, the renal measurements may differ from those mentioned in the literature. It is particularly important to obtain a growth chart for standard measurement of kidneys to avoid misdiagnosis of acute or chronic renal diseases, which may affect the renal size. However, no published data have been reported for the measurement of healthy kidneys in Sudanese children.

Thus, the aim of our study was to produce reference ranges for renal length in Sudanese children up to 5 years of age using ultrasonography.

\section{Materials and methods}

This cross-sectional study was done to measure the normal size of kidneys in pediatrics up to 5 years of age using ultrasound. The study was conducted at Khartoum state in the Emergency Department of Albuluk Pediatric Hospital and Jafar Ibn Ouf Referral Pediatric Hospital from March to June 2018. The study was approved by the ethics committee of Alzaiem Alazhari University, Faculty of Radiological Sciences and Medical Imaging. The study included 101 Sudanese children up to 5 years with normal renal function tests and urine analysis. The exclusion criteria were children with pathology in kidneys or medical conditions that may cause enlarged or reduced kidney size; these include malnutrition, sickle cell disease, and renal diseases (acute and chronic). In addition, children suffering from renal masses, cysts, hydronephrosis and abnormal renal function were excluded, regardless of the size of the kidneys.

The patients were examined using G.E. Logic F6, Denshi UF-4100, and Isaote with $3-4 \mathrm{MHz}$ with curvilinear probes using the electronic calipers for measurement. Blue aqueous gel and sterilized cotton were used for cleaning after each examination. A digital weighting scale was used to measure the weight, and an Infantometer was used to measure the height in children under 2 years. A Standometer was used to measure the height of children above 2 years. Verbal consent was taken from a relative of those children.

The sonographic examination began with the child lying supine on a couch. The kidneys were examined in a longitudinal and transverse section with the arms away from the chest wall, and the child was instructed to take shallow breaths if possible. Measurement of the kidneys was obtained with the subjects in the supine position, left lateral decubitus and right lateral decubitus. The longitudinal measurement was obtained from the coronal section, while thickness and width were measured in the transverse section.

Statistical analysis was performed using the standard Statistical Package for the Social Sciences (SPSS Inc., Chicago, IL, USA) version 16 for Windows. The normality of distribution of continuous variables was tested by onesample Kolmogorov-Smirnov test. Continuous variables were presented as mean \pm standard deviation (SD). For data with normal distribution, inter-group comparisons were performed using Student's t-test. Pearson's correlation coefficient (r) was used to determine the strength of the relationship between the two continuous variables. The linear regression model and coefficient of determination $\left(\mathrm{R}^{2}\right)$ were calculated. A probability value of $\mathrm{P}<0.05$ was considered statistically significant.

\section{Results}

A total of 101 Sudanese children participated in the study, aged from 1 month to 5 years old, with a mean of $31.37 \pm 18.79$ months; height ranged from $50 \mathrm{~cm}$ to $110 \mathrm{~cm}$, with a mean of $81.22 \pm 14.11 \mathrm{~cm}$; weight ranged from $3 \mathrm{~kg}$ to $29 \mathrm{~kg}$, with a of mean $12.66 \pm 4.99 \mathrm{~kg}$; and BMI ranged from $9.8 \mathrm{~kg} / \mathrm{m}^{2}$ to $36.36 \mathrm{~kg} / \mathrm{m}^{2}$, with a mean $18.77 \pm 4.65 \mathrm{~kg} / \mathrm{cm}^{2}$ (Table 1). The study revealed that mean measurements of the RK were $6.74 \pm 1.16 \mathrm{~cm}, 3.12 \pm 0.68 \mathrm{~cm}$, and $2.59 \pm 0.58 \mathrm{~cm}$ for length, width, and anteroposterior diameter, respectively, and for the LK $-6.98 \pm 1.10 \mathrm{~cm}, 3.25 \pm 0.65 \mathrm{~cm}$, and $2.74 \pm 0.60 \mathrm{~cm}$, respectively; the LK was longer than the RK (Table 1).

Table 1.

Clinical characteristics and kidney measurements in the study participants

\begin{tabular}{|l|c|c|c|}
\hline \multicolumn{1}{|c|}{ Variables } & Minimum & Maximum & Mean \pm SD \\
\hline Age $($ month) & 1 & 60 & $31.37 \pm 18.79$ \\
\hline Height $(\mathrm{cm})$ & 50 & 110 & $81.22 \pm 14.11$ \\
\hline Weight $(\mathrm{kg})$ & 3 & 29 & $12.66 \pm 4.99$ \\
\hline BMI $\left(\mathrm{kg} / \mathrm{cm}^{2}\right)$ & 9.80 & 36.36 & $18.77 \pm 4.65$ \\
\hline RK length $(\mathrm{cm})$ & 4.5 & 9.7 & $6.74 \pm 1.16$ \\
\hline RK width $(\mathrm{cm})$ & 1.5 & 5.0 & $3.12 \pm 0.68$ \\
\hline $\begin{array}{l}\text { RK anteroposterior } \\
\text { diameter }(\mathrm{cm})\end{array}$ & 1.2 & 4.2 & $2.59 \pm 0.58$ \\
\hline LK length $(\mathrm{cm})$ & 4.8 & 9.3 & $6.98 \pm 1.10$ \\
\hline LK width $(\mathrm{cm})$ & 2.1 & 5.2 & $3.25 \pm 0.65$ \\
\hline $\begin{array}{l}\text { LK anteroposterior } \\
\text { diameter }(\mathrm{cm})\end{array}$ & 1.8 & 4.4 & $2.74 \pm 0.60$ \\
\hline
\end{tabular}

The children were classified into 5 age groups (Table 2). The mean RLK increased steadily with age from $5.61 \pm 0.78 \mathrm{~cm}$ in Group 1 to $7.80 \pm 0.94 \mathrm{~cm}$ in Group 5. The study revealed that the mean RKL was $5.61 \pm 0.78 \mathrm{~cm}, 6.80 \pm 0.86 \mathrm{~cm}, 6.76 \pm 0.96$ $\mathrm{cm}, 7.29 \pm 0.68 \mathrm{~cm}$, and $7.80 \pm 0.94 \mathrm{~cm}$ for Groups $1,2,3,4$, and 5 , respectively. The RKL increased with increasing age, and there was a significantly strong difference with age $(P<0.01)$.

Table 2.

Mean lengths of the kidneys in different age groups*

\begin{tabular}{|l|c|c|}
\hline \multicolumn{1}{|c|}{ Age groups } & RKL $(\mathrm{cm})$ & LKL $(\mathrm{cm})$ \\
\hline Group 1: $\leq$ 1 year & $5.61 \pm 0.78$ & $5.93 \pm 0.80$ \\
\hline Group 2: 1 year, 1 month - 2 years & $6.80 \pm 0.86$ & $7.03 \pm 0.93$ \\
\hline Group 3: 2 years 1 month to 3 years & $6.76 \pm 0.96$ & $6.96 \pm 0.73$ \\
\hline Group 4: 3 years one month to 4 years & $7.29 \pm 0.68$ & $7.54 \pm 0.59$ \\
\hline Group 5: 4 years one month - 5 years & $7.80 \pm 0.94$ & $7.93 \pm 0.93$ \\
\hline
\end{tabular}

*The RKL and LKL increased with increasing age $(P<0.01)$ 
The study revealed that the mean LKL increased steadily with age from $5.93 \pm 0.80 \mathrm{~cm}$ in Group 1 to $7.93 \pm 0.93 \mathrm{~cm}$ in Group 5. The mean LKL was $5.93 \pm 0.80 \mathrm{~cm}, 7.03 \pm 0.93 \mathrm{~cm}, 6.96 \pm 0.73$ $\mathrm{cm}, 7.54 \pm 0.59 \mathrm{~cm}$, and $7.93 \pm 0.93 \mathrm{~cm}$ for Groups $1,2,3,4$, and 5 , respectively; there was also a significantly strong correlation between LK length and age $(P<0.01)$ (Table 2).

The study found a significant correlation between RK, LK length and age, height, weight, and BMI (Table 3).

Table 3.

Correlations between RK, LK length and age, height, weight, and BMI

\begin{tabular}{|c|c|c|c|}
\hline Variables & & RKL $(\mathrm{cm})$ & LKL $(\mathrm{cm})$ \\
\hline \multirow{2}{*}{ Age, month } & Pearson Correlation & $0.681^{*}$ & $0.674^{*}$ \\
\cline { 2 - 4 } & Sig. (2-tailed) & $<0.001$ & $<0.001$ \\
\hline \multirow{2}{*}{ Height, cm } & Pearson Correlation & $0.552^{*}$ & $0.622^{*}$ \\
\cline { 2 - 4 } & Sig. (2-tailed) & $<0.001$ & $<0.001$ \\
\hline \multirow{2}{*}{ Weight, kg } & Pearson Correlation & $0.626^{*}$ & $0.657^{*}$ \\
\cline { 2 - 4 } & Sig. (2-tailed) & $<0.001$ & $<0.001$ \\
\hline \multirow{2}{*}{ BMI, kg/cm ${ }^{2}$} & Pearson Correlation & $0.309^{*}$ & $0.259^{*}$ \\
\cline { 2 - 4 } & Sig. (2-tailed) & 0.002 & 0.009 \\
\hline
\end{tabular}

*-significant correlations

Regression analysis showed a linear relationship between the measurement of the kidneys and age. KL was estimated with the following equations: $\mathrm{RKL}=0.0422 \times$ age $($ month $)+5.4182 \mathrm{~cm}$ $\left(\mathrm{R}^{2}=0.4636\right), \mathrm{LKL}=0.0392 \times$ age $($ month $)+5.7472 \mathrm{~cm}\left(\mathrm{R}^{2}=4539\right)$, the mean $\mathrm{KL}=0.0407 \times$ age $+5.5827\left(\mathrm{R}^{2}=0.4801\right)($ Figure 1$)$.

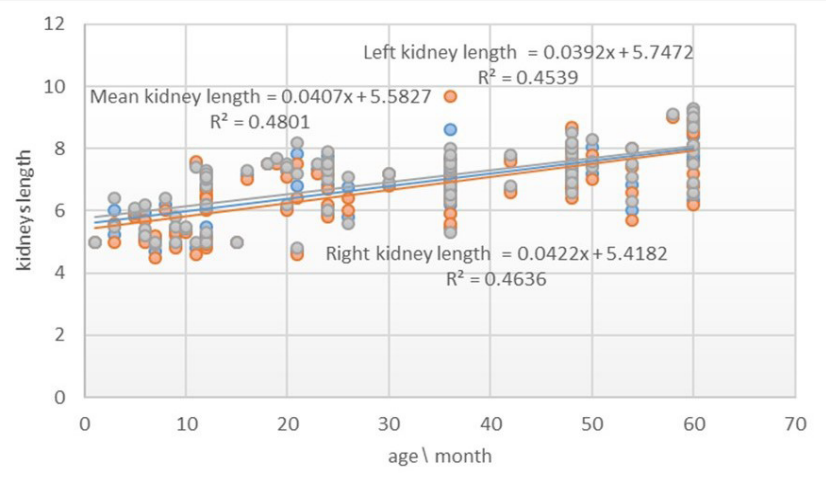

Fig. 1. Linear relationship between $R K$, LK length and age.

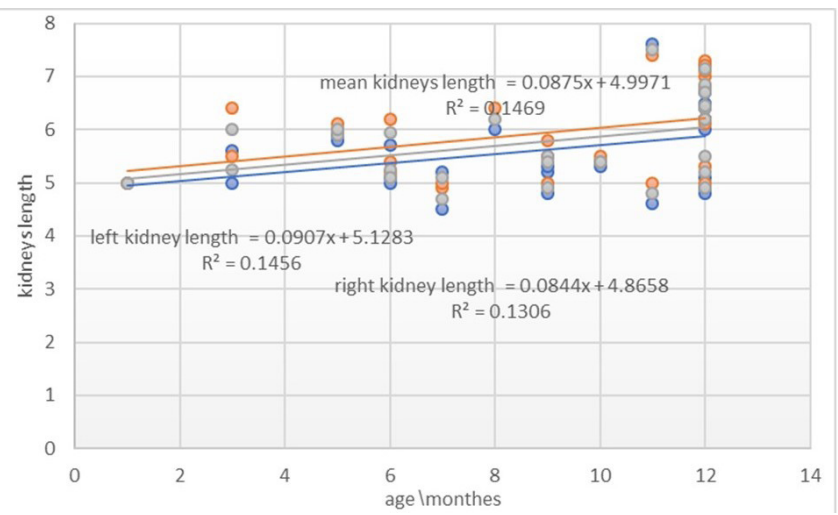

Fig. 2. Linear relationship between $R K, L K$ length and age (up to 1 year)
In Group 1 children, there were $R K L=0.0844 \times$ age $($ month $)$ $+4.8658 \mathrm{~cm}\left(\mathrm{R}^{2}=0.1306, \mathrm{LKL}=0.0907 \times\right.$ age $($ month $)+5.1283 \mathrm{~cm}$, and the mean $\mathrm{KL}=0.0875 \times$ age $($ month $)+4.9971 \mathrm{~cm}\left(\mathrm{R}^{2}=0.1469\right)$ (Figure 2).

The study predicted that in children of 13 months to 5 years, $\mathrm{RKL}=0.0309 \times$ age $($ month $)+5.9379 \mathrm{~cm}\left(\mathrm{R}^{2}=0.2109\right), \mathrm{LK}$ $\mathrm{L}=0.0286 \times$ age $($ month $)+6.2336 \mathrm{~cm}\left(\mathrm{R}^{2}=0.2099\right)$, and the mean $\mathrm{KL}=0.0298 \times \operatorname{age}($ month $)+6.0857 \mathrm{~cm}(\mathrm{R} 2=0.2266) \quad$ (Figure 3$)$. There was no significant difference in renal length according to gender. However, in boys both kidneys are slightly longer than in girls (Table 4 and Figure 4).

The study found that in children $\leq 1$ year, there was no significant correlation between the RKL and age, while a significant correlation was found between the LKL and age $(P<0.05)$. For children aged more than 1 year, there was a significant correlation between both renal lengths and age $(P<0.01)$ (Table 5)

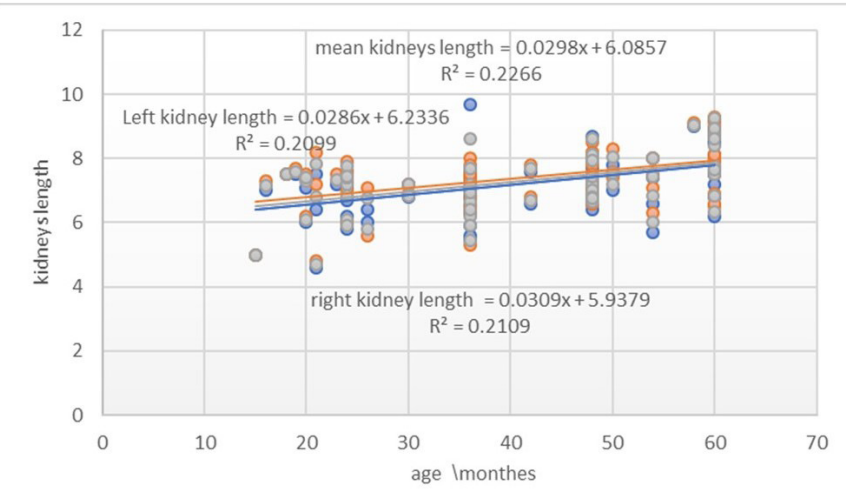

Fig. 3. Linear relationship between $R K, L K$ length and age (from 13 months to 5 years)

Table 4.

Comparison of kidney length in boys and girls

\begin{tabular}{|c|c|c|c|c|}
\hline Variables & Gender & Mean \pm SD & SE & P-value \\
\hline \multirow{2}{*}{ RKL $(\mathrm{cm})$} & Boy & $6.85 \pm 1.10$ & 0.1486 & \\
\cline { 2 - 4 } & Girl & $6.60 \pm 1.23$ & 0.1814 & \multirow{2}{*}{$>0.05$} \\
\hline \multirow{2}{*}{ LKL $(\mathrm{cm})$} & Boy & $7.04 \pm 0.96$ & 0.1308 & \\
\cline { 2 - 4 } & Girl & $6.88 \pm 1.22$ & 0.1810 & \\
\hline
\end{tabular}

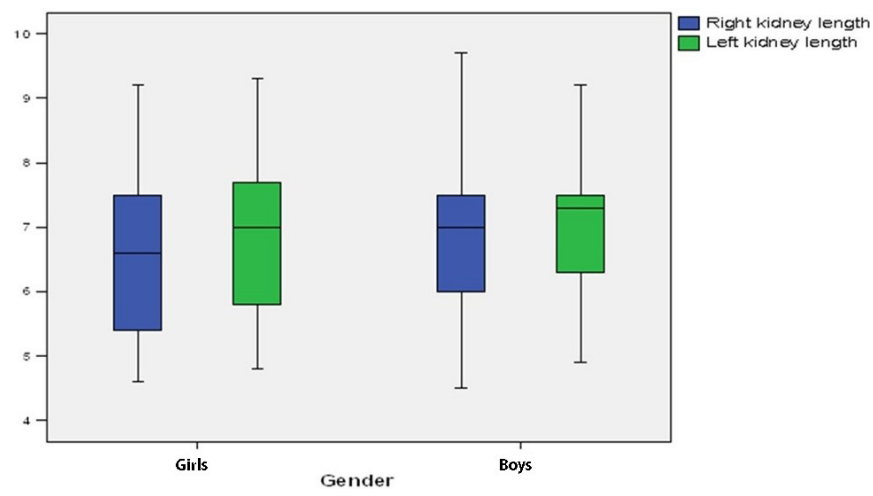

Fig. 4. Comparison of KL in boys and girls. 
Table 5.

Correlation between kidney length and age.

\begin{tabular}{|l|c|c|c|}
\hline \multicolumn{1}{|c|}{ Age } & & $\begin{array}{c}\text { RKL } \\
(\mathrm{cm})\end{array}$ & $\begin{array}{c}\text { LKL } \\
(\mathrm{cm})\end{array}$ \\
\hline \multirow{2}{*}{ 1month -1 year } & Pearson Correlation & 0.361 & $0.382 *$ \\
\cline { 2 - 4 } & Sig. (2-tailed) & 0.059 & 0.045 \\
\hline \multirow{2}{*}{ 1 year 1 month - 5 years } & Pearson Correlation & $0.459 *$ & $0.458 *$ \\
\cline { 2 - 4 } & Sig. (2-tailed) & $<0.001$ & $<0.001$ \\
\hline
\end{tabular}

*-significant correlations

\section{Discussion}

The growth chart of KL (Table 2) revealed that the mean renal length increased gradually with age, for 2 to 3 year olds, $6.76 \mathrm{~cm}$ vs. $6.96 \mathrm{~cm}$ for RK and LK, respectively. This finding is consistent with the growth chart of a study conducted of Korean children, which reported that the mean measurements of the kidneys of Korean children 2-3 years old were $6.79 \mathrm{~cm}$ and $7.07 \mathrm{~cm}$. In this study, the mean RKL and LKL were 7.29 $\mathrm{cm}$ and $7.54 \mathrm{~cm}$ for 3-4 year olds, and $7.80 \mathrm{~cm}$ and $7.93 \mathrm{~cm}$ for 4-5 year olds, respectively (Table 2 ). Oh et al. reported that the mean RKL and LKL were $7.06 \mathrm{~cm}$ and $7.27 \mathrm{~cm}$ for 3-4 year olds, and $7.53 \mathrm{~cm}$ and $7.77 \mathrm{~cm}$ for $4-5$ year olds, respectively. The difference between the mean measurement of our study and that of $\mathrm{Oh}$ et al. was 2 to $3 \mathrm{~mm}$. $^{(2)}$

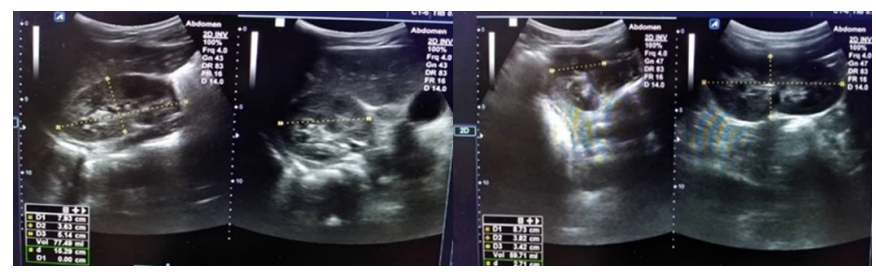

Fig. 5. US measurements of the kidneys in a 5-year-old child $(R K L=7.93 \mathrm{~cm}, L K L=8.73 \mathrm{~cm})$.

The present study found that there was no significant correlation between RKL and age in children up to 1 year, with a slightly significant correlation found between LKL and age. On the other hand, we found a significant correlation in both kidney lengths with age in children more than 1 year old. Oh et al. found a significant difference before and after 20 months of age. ${ }^{(2)}$

In pediatrics, the LK is longer than the RK. Previous studies conducted in Turkey by Özdikici, ${ }^{(3)}$ in India by Otiv et al. ${ }^{(4)}$ and Thapa et al..$^{(5)}$ agreed with our findings. They reported that the LK is longer than the RK.

Our study found that there was a significant correlation between age, height, weight, and BMI of participants, and kidney measurements $(P<0.001)$. Oh et al., ${ }^{(2)}$ Thapa et al., ${ }^{(5)}$ Gavela et al., ${ }^{(6)}$ and Ravikumar et al. ${ }^{(7)}$ also found that the renal length correlated with different parameters such as age, weight, height. Oh et al. ${ }^{(2)}$ and Thapa et al. ${ }^{(5)}$ found the correlation was more between KL and height than age and weight. Furthermore, our findings are similar to studies conducted by Zerin and Blane, ${ }^{(8)}$ who reported a strong correlation between KL and height. Body weight showed the best correlation with both KLs, according to Warnakulasuriya et al., ${ }^{(9)}$ who found that weight is the most influential factor in both KLs. Additionally, Pantoja Zuzuárregui et al. ${ }^{(10)}$ found that BMI is well-correlated with renal length. In contrast, Kim et al. ${ }^{(11)}$ stated that a weak correlation was found between BMI and renal length, compared to the correlation between BMI and height and weight. Our findings supported the strongest correlation of renal length with age, followed by weight, then height, and the least one with BMI.

Regarding the correlation between gender and $\mathrm{KL}$ of children, this study found no significant difference in renal length according to gender. Most of the previous studies supported this finding and reported that girls have smaller kidneys than boys do. ${ }^{(4,12-15)}$

In our study we found that in children $\leq 1$ year the mean $\mathrm{KL}=.0875 \times$ age $($ month $)+4.9971 \mathrm{~cm}\left(\mathrm{R}^{2}=0.1469\right)$ and in children of 13 months to 5 years the mean $\mathrm{KL}=0.0298 \times$ age $($ month $)+6.0857 \mathrm{~cm}$ $\left(\mathrm{R}^{2}=0.2266\right)$.

These results are consistent with Rosenbaum et al. ${ }^{(16)}$ who found that the mean renal lengths per $\mathrm{cm}$ for children older than 1 year were $6.79+0.22 \times$ age $($ year $)\left(R^{2}=0.70\right)$, and for children younger than 1 year: $4.98+0.155 \times$ age $($ month) $\left(\mathrm{R}^{2}=0.34\right)$. The minor difference in our equation in this study for children older than 1 year was the inclusion of children up to 5 years of age only, while they included children from several hours to 19 years.

For Korean children, Kim et al. ${ }^{(17)}$ found that

$\mathrm{KL}(\mathrm{mm})=45.953+1.064 \times \operatorname{age}(\leq 24 \mathrm{months})\left(\mathrm{R}^{2}=0.720\right)$ or $62.173+0.203 \times$ age $(>24$ months $)\left(\mathrm{R}^{2}=0.711\right)$.

Akhavan et al. ${ }^{(18)}$ stated that in children 1 year of age and more, $\mathrm{KL}(\mathrm{cm})=$ age $($ years $) \times 0.3+6\left(\mathrm{R}^{2}=0.81\right)$, but in infants less than 1 year, the renal length was poorly estimated by a simple age-based formula.

The study concluded that the renal length in pediatric up to 5 years old can be predicted by age using the following regression equations: $\mathrm{RKL}=0.0422 \times$ age $+5.4182 \mathrm{~cm}\left(\mathrm{R}^{2}=0.4636\right)$, $\mathrm{LKL}=0.0392 \times$ age $+5.7472 \mathrm{~cm} \quad\left(\mathrm{R}^{2}=0.4539\right)$. The mean $\mathrm{KL}$ in children $\leq$ 1years old: $0.0875 \times$ age $+4.9971 \mathrm{~cm}\left(\mathrm{R}^{2}=0.1469\right)$. The mean KL in those of 1 year+ 1 day to 5 years: $0.0298 \times$ age $+6.0857 \mathrm{~cm}$ $\left(\mathrm{R}^{2}=0.2266\right)$.

Age is an important influencing factor for assessing KL since there is a strong, significant correlation between age and $\mathrm{KL}$ ( $\mathrm{r}=0.68$ for RK and $\mathrm{r}=0.67$ for $\mathrm{LK}, P<0.01$ ). There was no significant difference in renal length according to gender. The LK is larger than the RK in pediatric patients up to 5 years. Understanding the normal measurements of the children's kidneys is important to reduce the misdiagnosis of renal diseases, which may alter the kidneys' size in pediatrics.

\section{Competing Interests} interests.

The authors declare that they have no competing

\section{References}

1. Kadioglu A. Renal measurements, including length, parenchymal thickness, and medullary pyramid thickness, in 
healthy children: what are the normative ultrasound values? AJR Am J Roentgenol. 2010;194(2):509-515. doi:10.2214/ AJR.09.2986

2. Oh MS, Hwang G, Han S, Kang HS, Kim SH, Kim YD, et al. Sonographic Growth Charts for Kidney Length in Normal Korean Children: a Prospective Observational Study. J Korean Med Sci. 2016;31(7):1089-1093. doi:10.3346/ jkms.2016.31.7.1089

3. Özdikici M. Ultrasonographic assessment of renal length in 310 Turkish children in the Eastern Anatolia region. South African Journal of Child Health. 2018;12(1):34-37. doi:10.7196/SAJCH.2018.v12i1.1405.

4. Otiv A, Mehta K, Ali U, Nadkarni M. Sonographic measurement of renal size in normal Indian children. Indian Pediatr. 2012;49(7):533-536. doi:10.1007/s13312-012-0120-7 5. Thapa NB, Shah S, Pradhan A, Rijal K, Pradhan A, Basnet S. Sonographic Assessment of the Normal Dimensions of Liver, Spleen, and Kidney in Healthy Children at Tertiary Care Hospital. Kathmandu Univ Med J (KUMJ). 2015;13(52):286291. doi:10.3126/kumj.v13i4.16825

6. Gavela T, Sánchez Bayle M, Gómez Mardones G, Gallego S, Martínez-Pérez J, Moya MT. [Ecographic study of kidney size in children]. Nefrologia. 2006;26(3):325-329. \{Article in Spanich].

7. Ravikumar N, Anita S, Venkateshwara reddy C. To Determine the Renal Size in Normal Children by Ultrasonography. IOSR Journal of Dental and Medical Sciences (IOSR-JDMS). 2016;15(4 Ver. I):41-45. doi: 10.9790/0853-1504014145.

8. Zerin JM, Blane CE. Sonographic assessment of renal length in children: a reappraisal. Pediatr Radiol. 1994;24(2):101-106. doi:10.1007/BF02020164

9. Warnakulasuriya DTD, Peries PPUC, Rathnasekara YAC, Jayawardena KTM, Upasena A, Wickremasinghe AR. Ultrasonographic parameters of the liver, spleen and kidneys among a cohort of school children in Sri Lanka. BMC Pediatr. 2017;17(1):192. Published 2017 Nov 16. doi:10.1186/s12887017-0943-4
10. Pantoja Zuzuárregui JR, Mallios R, Murphy J. The effect of obesity on kidney length in a healthy pediatric population. Pediatr Nephrol. 2009;24(10):2023-2027. doi:10.1007/s00467-009-1202-1

11. Kim JH, Kim MJ, Lim SH, Kim J, Lee MJ. Length and volume of morphologically normal kidneys in korean children: ultrasound measurement and estimation using body size. Korean J Radiol. 2013;14(4):677-682. doi:10.3348/ kjr.2013.14.4.677

12. Scott JE, Hunter EW, Lee RE, Matthews JN. Ultrasound measurement of renal size in newborn infants. Arch Dis Child. 1990;65(4 Spec No):361-364. doi:10.1136/adc.65.4_spec_ no. 361

13. Safak AA, Simsek E, Bahcebasi T. Sonographic assessment of the normal limits and percentile curves of liver, spleen, and kidney dimensions in healthy schoolaged children. J Ultrasound Med. 2005;24(10):1359-1364. doi:10.7863/jum.2005.24.10.1359

14. Eze CU, Agwu KK, Ezeasor DN, Agwuna KK, Aronu AE, Mba EI. Sonographic Biometry of Normal Kidney Dimensions among School-age Children in Nsukka, Southeast Nigeria. West Indian Med J. 2014;63(1):46-53. doi:10.7727/ wimj.2013.010

15. Coombs PR, Lavender I, Leung MYZ, Woods JC, Paul E, Webb N, Ditchfield M. Normal sonographic renal length measurements in an Australian pediatric population. Pediatr Radiol. 2019;49(13):1754-1761. doi:10.1007/s00247-01904486-2

16. Rosenbaum DM, Korngold E, Teele RL. Sonographic assessment of renal length in normal children. AJR Am J Roentgenol. 1984;142(3):467-469. doi:10.2214/ajr.142.3.467 17. Kim IO, Cheon JE, Lee YS, Lee SW, Kim OH, Kim JH, et al. Kidney length in normal Korean children. J Korean Soc Ultrasound Med. 2010;29:181-188.

18. Akhavan A, Brajtbord JS, McLeod DJ, Kabarriti AE, Rosenberg HK, Stock JA. Simple, age-based formula for predicting renal length in children. Urology. 2011;78(2):405410. doi:10.1016/j.urology.2011.01.008 